INFLATION WITH COVID CONSUMPTION BASKETS

Alberto Cavallo

WORKING PAPER 27352 
NBER WORKING PAPER SERIES

\title{
INFLATION WITH COVID CONSUMPTION BASKETS
}

\author{
Alberto Cavallo \\ Working Paper 27352 \\ http://www.nber.org/papers/w27352 \\ NATIONAL BUREAU OF ECONOMIC RESEARCH \\ 1050 Massachusetts Avenue \\ Cambridge, MA 02138 \\ June 2020, Revised July 2020
}

I am grateful to Florencia Hnilo for excellent research assistance, to John Friedman for sharing the Opportunity Insights data, to Caroline Coughlin and Manuel Bertolotto for assistance with the CPI data, and to Rafael Di Tella for helpful comments and suggestions. Financial support for the research in this paper was provided by Harvard Business School. I am also an ad-honorem member of the Technical Advisory Committees of the US Bureau of Labor Statistics (BLS). The views expressed herein are those of the author and do not necessarily reflect the views of the National Bureau of Economic Research.

The author has disclosed a financial relationship of potential relevance for this research. Further information is available online at http://www.nber.org/papers/w27352.ack

NBER working papers are circulated for discussion and comment purposes. They have not been peer-reviewed or been subject to the review by the NBER Board of Directors that accompanies official NBER publications.

(C) 2020 by Alberto Cavallo. All rights reserved. Short sections of text, not to exceed two paragraphs, may be quoted without explicit permission provided that full credit, including (C) notice, is given to the source. 
Inflation with Covid Consumption Baskets

Alberto Cavallo

NBER Working Paper No. 27352

June 2020, Revised July 2020

JEL No. C43,E21,E31

\title{
ABSTRACT
}

The Covid-19 Pandemic has led to changes in consumer expenditure patterns that can introduce significant bias in the measurement of inflation. I use data collected from credit and debit transactions in the US to update the official basket weights and estimate the impact on the Consumer Price Index (CPI). I find that the Covid inflation rate is higher than the official CPI in the US, for both headline and core indices. I also find similar results with Covid baskets in 10 out of 16 additional countries. The difference is significant and growing over time, as socialdistancing rules and behaviors are making consumers spend relatively more on food and other categories with rising inflation, and relatively less on transportation and other categories experiencing significant deflation.

\author{
Alberto Cavallo \\ Harvard Business School \\ Morgan Hall 287 \\ Soldiers Field \\ Boston, MA 02163 \\ and NBER \\ acavallo@hbs.edu
}




\section{Introduction}

The Covid-19 Pandemic has led to lockdowns, mobility restrictions, and social-distancing rules that are dramatically changing consumer expenditure patterns in many countries. ${ }^{1}$ In partic- $^{-}$ ular, consumers are spending less on transportation, hotels, restaurants, and recreation, while expenditures on food and other groceries have increased in both absolute and relative terms.

These sudden changes in expenditure patterns can introduce significant biases in the Consumer Price Indices (CPIs) used to measure inflation, as noted by Diewert and Fox (2020). Most National Statistical Offices (NSOs) update their CPI expenditure weights once a year, often with lagged expenditure data. The US Bureau of Labor Statistics (BLS), for example, updated the weights in December 2019 using expenditure information collected back in 2017-2018. ${ }^{2}$ While this practice may be reasonable in normal times, it makes inflation indices much harder to interpret during the Pandemic, as recently noted by central bankers such as Tenreyro (2020) and Lane (2020).

In this paper, I empirically study the impact that changes in expenditure patterns are having on the measurement of CPI inflation in 18 countries. I use high-frequency estimates of spending based on transactional data to build updated CPI weights and compute alternative "Covid Basket" price indices.

I start with the US, where card-based expenditure data are publicly available as part of the Opportunity Insights Economic Tracker at Harvard and Brown University, described in Chetty et al. (2020). I first show that headline Covid inflation is higher than what the CPI reflects. By May 2020, the annual inflation rate of the US Covid index was $0.95 \%$, compared to only $0.13 \%$ of the equivalent CPI (all-items, US city average, not seasonally adjusted). The difference is significant and growing over time, as new social-distancing rules and preferences prevent consumer spending in categories that are experiencing deflation, such as transportation, and induce more expenditure in food and other groceries, where prices are increasing over time. I also find similar results when I focus on the Core CPI, implying that the bias is not limited to consumer spending on food

\footnotetext{
${ }^{1}$ See Chetty et al. (2020), Carvalho et al. (2020), Baker et al. (2020), Andersen et al. (2020), Dunn et al. (2020), and Coibion et al. (2020).

${ }^{2}$ Most NSOs compute a Lowe Index formula at upper levels of aggregation. This introduces small adjustments that account for relative price changes across categories every month, but they have little impact on the basket weights because quantities are assumed to be fixed. See Bureau of Labor Statistics (2020) for an archive of BLS weights over time.
} 
and energy. Furthermore, I show that low-income households are experiencing more inflation during the crisis, with an annual inflation rate of $1.12 \%$ in May 2020 , compared to just $0.57 \%$ for high-income households.

Next, I estimate the impact in 17 additional countries. To build a unique Covid basket for each country, I update the official CPI weights with the same relative changes across categories observed in the US. Consistent with the previous results, I find that in 12 countries the Covid inflation rate is higher than that of the official CPI. In the other 5 cases, however, the inflation rate is lower, highlighting the fact that the CPI bias can go in any direction, depending not only on the changes in the basket weights but also on the inflation rates experienced by each CPI subcategory.

My results have important implications for policy-makers trying to respond to the crisis. They suggest that the cost of living for consumers is higher than estimated by the official CPI, especially for low-income consumers. The welfare effects are particularly relevant during this crisis, where a large share of the population is becoming unemployed. My results also highlight the divergence in sectoral inflation rates that reflect different demand and supply shocks across categories in many countries. This particular behavior of prices during the Pandemic tends to amplify the CPI bias emphasized in this paper.

\section{Data and Methodology}

To build the "Covid Basket," I start with daily measures of the change in US consumption patterns since January 2020, available at the Opportunity Insights (OI) Tracker ${ }^{3}$. These estimates, shown in Figure 1, are produced using transactional data collected from credit and debit card transactions in the US, as described by Chetty et al. (2020).

\footnotetext{
${ }^{3}$ See https://opportunityinsights.org/
} 


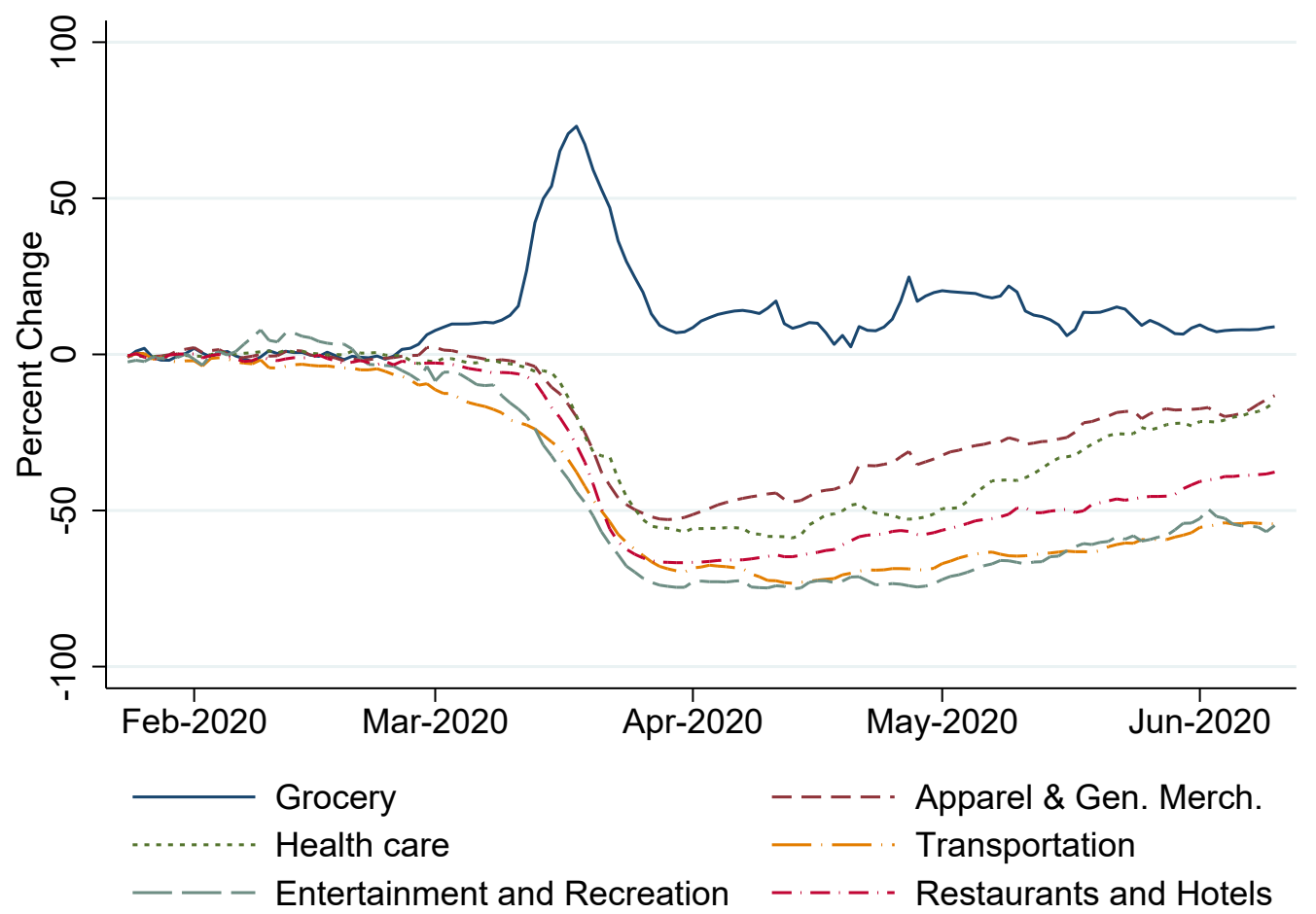

Figure 1: Changes in US Consumer Spending During the Pandemic

Notes: This graph shows the cumulative expenditure change across categories of goods and services in the US since January 2020. These estimates are computed by Chetty et al. (2020) using data collected from credit and debit card transactions. The data is publicly available at the Opportunity Insights (OI) website (opportunityinsights.org).

I combine these estimates with official CPI data from January 2019 to May 2020, obtained from the official NSO in each country, including the Bureau of Labor Statistics in the US. In most cases, I use the CPI sector series that form the first level of disaggregation of the headline CPI (all-items, not-seasonally adjusted), as well as the latest available weights in the official CPI basket.

The matching of the OI categories with the CPI sectors requires some assumptions, as detailed in the Appendix. To improve the correspondence, I split the CPI for "Food and Beverages" into three additional subcategories. About six categories are then closely matched in both datasets. For "Food at Home" and "Alcoholic Beverages," I use the OI "Grocery" category. For "Food Away from Home," I use the OI category for "Restaurants and Hotels." For "Other Goods and Services," I assume that the expenditure changes are equal to those of the whole OI basket. Finally, for "Housing" and "Education and Communication," I assume that expenditures in these categories have not changed, which seems a reasonable assumption during the first months 
of the Pandemic.

To estimate the expenditure shares in the Covid basket, I start with the latest official CPI weights and multiply them by the average percentage change in the corresponding expenditure category each month. The new weights are then re-computed as a share of the total, to account for the fact that total expenditure is also falling over time.

Formally, the Covid weights are given by:

$$
s_{t}^{i}=\frac{P_{t}^{i} Q_{t}^{i}}{\sum_{i} P_{t}^{i} Q_{t}^{i}}=\frac{s_{0}^{i} \Delta e^{i}}{\sum_{i} s_{0}^{i} \Delta e^{i}}
$$

where $P_{t}^{i}$ and $Q_{t}^{i}$ are the prices and quantities of CPI category $i$ at time $t$, and $\Delta e^{i}=\frac{P_{t}^{i} Q_{t}^{i}}{P_{0}^{i} Q_{0}^{i}}$ is the change in expenditure. Equation 1 highlights the fact that these are relative weights, so the importance of a category in the basket can change even when its expenditure is not affected.

Finally, the CPI and Covid price indices are computed using the weighted sum of the changes in the official CPI sectoral indices, using weights $s_{0}^{i}$ and $s_{t}^{i}$, respectively. Note the fixed-basket CPI is Laspeyres index, which traditionally results in higher inflation because it does not allow for the possibility that consumers shift their spending away from categories experiencing relatively more inflation. By using more current expenditure weights in the Covid Index, I am allowing for this possibility, which makes my results with the Covid basket more surprising. ${ }^{4}$

\section{Impact on US Inflation}

In this section, I focus on the US, where detailed high-frequency Covid expenditure estimates are publicly available. I first look at the impact on the all-items CPI, expand the results to the Core CPI, and discuss some policy and welfare implications comparing results for both low and high-income consumers.

\subsection{All-items CPI}

The all-items CPI for urban consumers (CPI-U) is the main "headline" measure of inflation in the US. Table 1 shows the impact that the changes in expenditure shares across categories had

\footnotetext{
${ }^{4}$ The Covid index is not a Paasche index because I am not fixing the basket weights to the last period. Instead, my method is closer to the "Chained CPI" produced by the BLS (C-CPI-U). Unfortunately, the BLS can only update expenditure weights gradually, which results in a preliminary C-CPI-U index that does not fully reflect spending patterns until a year later, when a final version is published. In fact, in the Appendix I show that the C-CPI-U has had less inflation during the Pandemic than the CPI-U, the benchmark all-items CPI used in this paper.
} 


\begin{tabular}{|c|c|c|c|c|}
\hline & \multicolumn{2}{|c|}{$\begin{array}{l}\text { Monthly Inflation Rate } \\
\text { (1-month change, \%) }\end{array}$} & \multicolumn{2}{|c|}{$\begin{array}{l}\text { Annual Inflation Rate } \\
\text { (12-month change, \%) }\end{array}$} \\
\hline & CPI & Covid CPI & CPI & Covid CPI \\
\hline January & 0.39 & 0.39 & 2.50 & 2.50 \\
\hline February & 0.27 & 0.28 & 2.35 & 2.35 \\
\hline March & -0.22 & -0.12 & 1.56 & 1.67 \\
\hline April & -0.69 & -0.09 & 0.35 & 1.05 \\
\hline May & -0.02 & 0.11 & 0.13 & 0.95 \\
\hline
\end{tabular}

Table 1: US Inflation Rates During the Covid Pandemic

Notes: This table shows the monthly and annual inflation rate in the all-items, US city average, not seasonally adjusted CPI, and an equivalent index constructed using estimates of the consumption expenditure shares during the Covid Pandemic.

on this index for every month since the Pandemic started.

As expected, the CPI and Covid CPI have nearly identical monthly inflation rates in January and February because there were no significant expenditure differences. By March, when the Pandemic hit the US, both indices started showing significant deflation. But the Covid index had only half the deflation shown by the fixed-basket CPI. In April, the difference became larger, with the Covid CPI falling by only $-0.09 \%$ compared to a fall of $-0.69 \%$ in the CPI. In fact, that month the trend in the Covid CPI was already rebounding. In May, the Covid CPI has a positive inflation rate, while the CPI was still experiencing some deflation.

Although the magnitude of the bias changes over time, every single month has added more inflation to the Covid index, so that the impact on the annual inflation rate is already significant, as shown in the last two columns of Table 1. By May, the Covid index was experiencing an annual inflation rate equal to $0.95 \%$ compared to just $0.13 \%$ in the official CPI.

To understand why the Covid index has more inflation, consider the CPI patterns and weights shown in Table 2 for the month of April 2020, when the difference was largest. The first column shows a comprehensive list of all the CPI categories that compose the all-items index. The second column shows the monthly CPI sector inflation for that month. The third and fourth columns show the CPI and Covid weights. Finally, the last two columns show the incidence that each category has on the total inflation rate. The incidence is simply the monthly inflation rate multiplied by the weight, and the sum of all the numbers in the last two columns equals the $-0.69 \%$ and $-0.09 \%$ monthly inflation rates for CPI and Covid CPI during the month of April. 


\begin{tabular}{|c|c|c|c|c|c|}
\hline \multirow[b]{2}{*}{ CPI Category } & \multirow{2}{*}{$\begin{array}{c}\text { Monthly } \\
\text { CPI Inflation }\end{array}$} & \multicolumn{2}{|c|}{ Weight } & \multicolumn{2}{|c|}{ Incidence } \\
\hline & & CPI & Covid CPI & CPI & Covid CPI \\
\hline Food at Home & 2.67 & 7.58 & 11.28 & 0.20 & 0.30 \\
\hline Alcoholic Beverages & 0.30 & 1.02 & 1.52 & 0.00 & 0.00 \\
\hline Apparel & -4.38 & 2.81 & 2.20 & -0.12 & -0.10 \\
\hline Housing & -0.03 & 42.11 & 55.80 & -0.01 & -0.02 \\
\hline Medical Care & 0.28 & 8.83 & 5.60 & 0.02 & 0.02 \\
\hline Transportation & -4.97 & 15.74 & 6.25 & -0.78 & -0.31 \\
\hline Recreation & -0.27 & 5.82 & 2.23 & -0.02 & -0.01 \\
\hline Education and Communication & 0.13 & 6.77 & 8.97 & 0.01 & 0.01 \\
\hline Food Away from Home & 0.15 & 6.19 & 3.13 & 0.01 & 0.00 \\
\hline Other Goods and Services & -0.04 & 3.13 & 3.03 & 0.00 & 0.00 \\
\hline
\end{tabular}

Table 2: US CPI Weights and Incidence - April 2020

Notes: The CPI weight is the share of expenditure in a given category over total expenditures. Note that categories that experience no change in spending over time can have higher Covid weights as a share of the decreasing total expenditure basket. The incidence is the monthly inflation rate multiplied by the weight. The sum of all the category incidence numbers is equal to the monthly inflation rate.

Table 2 shows that the US Covid inflation rate was higher in April because there was more weight in categories that had a positive inflation rate, and less weight in categories experiencing significant deflation. In particular, the weight for "Food at Home" rose from $7.58 \%$ to $11.28 \%$, increasing the incidence of this category by $0.1 \%$. At the same time, the weight for "Transportation" fell from $15.74 \%$ to $6.25 \%$, increasing the incidence on the total monthly inflation rate by about $0.47 \%$. The weights of "Housing" and "Education and Communication" also rose significantly. However, these two categories had little impact on Covid inflation so far because their sectoral inflation rates are close to zero.

\subsection{Core CPI}

Although most of the difference comes from the changes in spending on food and fuel, a similar bias is present in the Core CPI index that excludes these categories, as shown in the Appendix. By May, the Core Covid annual inflation rate was $1.59 \%$ compared to the $1.20 \%$ in the official Core index..$^{5}$

Why does the Core CPI have more inflation with a Covid basket, even after food and energy

\footnotetext{
${ }^{5}$ To build the Core indices, I dropped all food CPI series and further split the "Housing" and "Transportation" series to remove their energy components. I also made similar assumptions for the consumer spending patterns at the category level, with details provided in the Appendix.
} 
are excluded? The reason is that there is less spending weight in non-energy transportation subcategories with significant deflation, such as "Public Transportation" and "New and Used Motor Vehicles." Detailed spending patterns for these categories are not available, but Figure 1 shows the share of U.S. consumer spending in the broader "Transportation" sector is taking longer to recover that in other categories, suggesting that while the magnitude of the bias is smaller with the Core CPI, its effects may end up being more persistent over time.

\subsection{Income Levels and Policy Implications}

These findings imply that the cost of living for consumers is rising faster during the Covid crisis. This can, in turn, have important welfare implications across different income groups. A large literature has studied how inflation varies across income levels. Earlier papers by Michael (1979), Hagemann (1982), Hobijn and Lagakos (2005) focused on differences in expenditures at upper levels of aggregation. More recently, papers with scanner data such as Kaplan and SchulhoferWohl (2017), Jaravel (2019), and Argente and Lee (2017) have emphasized additional mechanisms that affect the inflation experienced by low-income households within narrow categories of goods. In particular, Jaravel (2019) found that annual inflation in the US for households in the bottom income quintile was on average nearly 0.4\% higher for the period 2004-2015.

To explore the impact that the Covid crisis is having on the inflation rate experienced by different households, I use data from the 2018 BLS Consumer Expenditure Survey (CEX) to build upper-level expenditure weights for the lowest and highest quintiles of the household income distribution. I then update these weights using monthly spending for equivalent income quintiles provided by Opportunity Insights. More details on the construction of these weights are provided in the Appendix.

Figure 2 shows the annual inflation rate for the income-level indices, as well as the benchmark official and Covid CPIs. During 2019, low-income households were already experiencing more inflation due to the fact that they spend relatively more on food. After March 2020, the Pandemic exacerbated the difference. Using Covid weights, the low-income households had an annual inflation rate of $1.12 \%$ in May 2020, compared to just $0.57 \%$ for high income households.

The changes in consumption patterns during Covid increased the inflation rate for both income groups, but the fact that low-income households spend relatively more on food than in 
transportation has exacerbated the difference in inflation rates during the first months of the crisis. ${ }^{6}$ A complete welfare calculation requires knowing the persistence of these effects and the changes in incomes during the crisis, but as far as inflation is concerned, real consumption for lower-income households is falling faster than the headline CPI suggests.

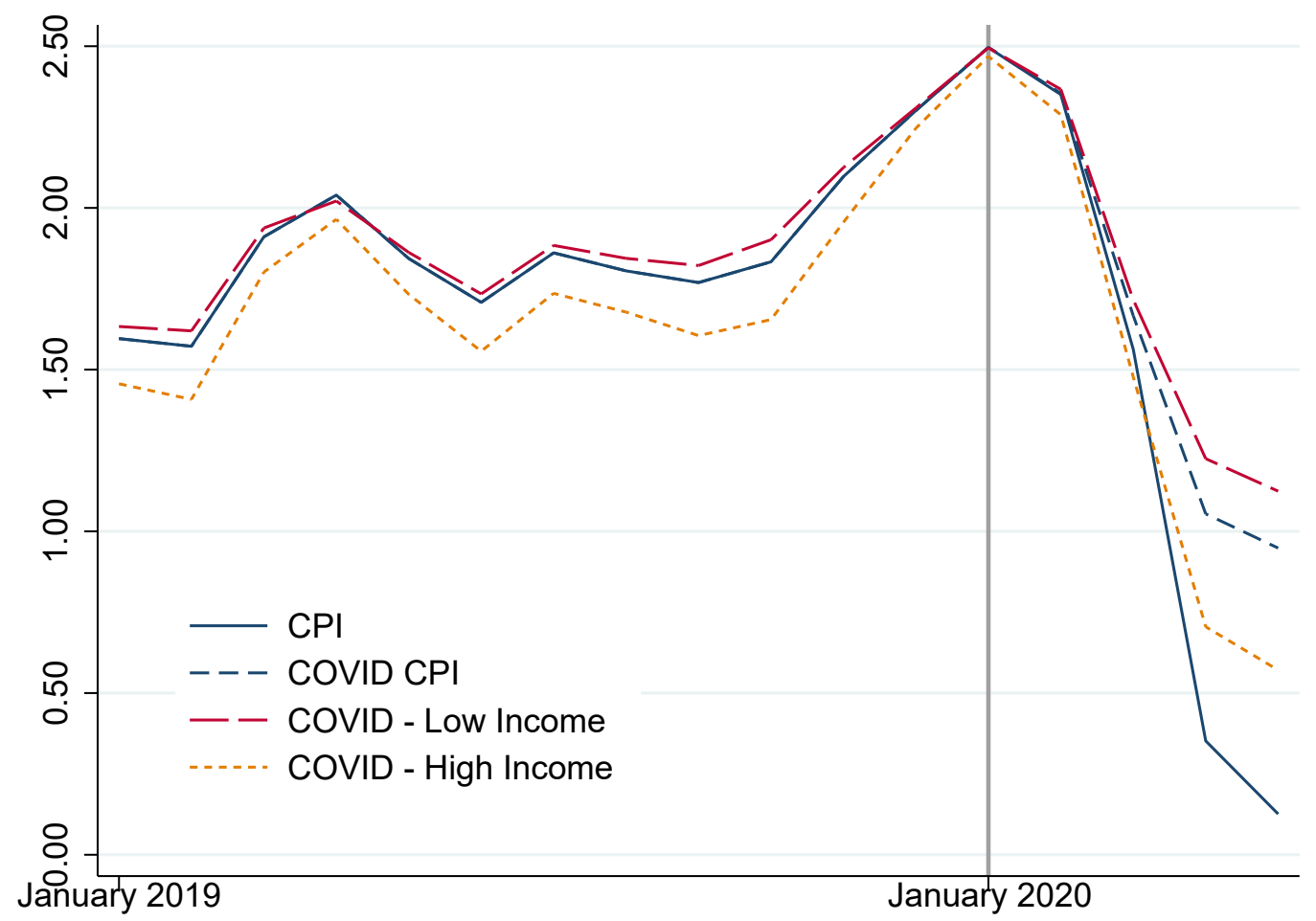

Figure 2: US Annual Inflation with Covid Expenditure Baskets

Notes: The CPI and Covid CPI are plots of the same indices shown in Table 1. The Covid Low (High) Income index uses CEX expenditure weights for households in the lowest (highest) quintile of the income distribution. These weights remain constant for 2019, and after January 2020, are updated using the changes in spending patterns for equivalent quintiles computed by Opportunity Insights. See the Appendix for details.

For Central Bankers and others interested in inflation dynamics, my results highlight the importance of monitoring sectoral inflation trends during the Pandemic. The combination of negative demand and supply shocks suggests that aggregate inflation is likely to remain relatively stable in the short-run compared to the 2008-2010 Financial Crisis. This is particularly true when we take into account the changes in consumption patterns. Furthermore, my results could help explain the sudden increase in consumer inflation expectations in April and May, as reported in the Michigan Survey of Consumers. ${ }^{7}$ This behavior is consistent with a growing literate that

\footnotetext{
${ }^{6}$ In proportional terms, the recent increase in inflation relative to a fixed-basket index is smaller for lower-income households because the changes in spending patterns have been less persistent. See the Appendix for details

${ }^{7}$ See Curtin (2020)
} 
suggests that consumers use their own purchasing experiences to form expectations about future inflation. $^{8}$

\section{Impact in other Countries}

In this section, I show results in 17 additional countries. The methodology remains the same except for two differences. First, these countries use the COICOP classification system, which is different from the one applied by the BLS in the US. ${ }^{9}$ Nevertheless, the matching and assumptions are similar to those used for the US, as shown in the Appendix. Second, I do not have updated expenditure estimates in other countries, so I assume that the change in spending for each category during the Pandemic is the same as in the US. This provides an approximation to the potential impact that the Covid consumption basket has in each of these countries. In the end, the Covid shares are very different across countries because I start with the official CPI weights and only update with the assumption that the relative changes in spending are similar to those experienced in the US.

Table 3 compares the CPI and Covid annual inflation by May 2020. Detailed weights and incidence by category are shown in the Appendix.

\footnotetext{
${ }^{8}$ See Coibion and Gorodnichenko (2015), Cavallo et al. (2017), and D'Acunto et al. (2019).

${ }^{9}$ See UN (2018) "Classification of Individual Consumption According to Purpose (COICOP)" for details.
} 
Annual Inflation

\begin{tabular}{lrr} 
& \multicolumn{2}{c}{ Annual Inflation } \\
& \multicolumn{2}{c}{$(12$-month change, $\%)$} \\
\cline { 2 - 3 } Country & CPI & Covid CPI \\
\hline & & \\
Brazil & 1.65 & 2.53 \\
Uruguay & 10.99 & 11.81 \\
US & 0.13 & 0.95 \\
Korea & -0.45 & 0.04 \\
Chile & 2.68 & 3.05 \\
France & 0.55 & 0.88 \\
Colombia & 2.72 & 2.97 \\
Canada & -0.34 & -0.12 \\
Turkey & 11.56 & 11.73 \\
Japan & 0.07 & 0.22 \\
Spain & -0.18 & -0.09 \\
UK & 0.59 & 0.67 \\
Argentina & 43.38 & 43.45 \\
& & 0.53 \\
Germany & 0.57 & -0.91 \\
Ireland & -0.85 & 1.13 \\
Netherlands & 1.20 & 0.52 \\
Italy & 0.86 & -0.10 \\
Greece & 0.25 & \\
& &
\end{tabular}

Table 3: CPI and Covid Inflation in May 2020

Notes: The top panel shows countries where the Covid inflation is higher than the fixed-basket CPI. The bottom panel shows countries where the Covid inflation is lower than the fixed-basket CPI. Covid inflation rates are constructed using official CPI weights in each country updated by the relative changes across categories observed in US data. Details on the incidence of CPI categories on the monthly inflation rate in each country are shown in the Appendix.

In the top panel, I show those countries where the Covid Inflation rate is higher than that of the fixed-basket official CPI, ranked by the percentage point difference. Consistent with the US results, in most of these countries the higher Covid inflation rate is driven by an increase in spending in "Food and Beverages", which is experiencing more inflation, and a decrease in the weight of "Transportation", which is having significant deflation. Brazil is at the top because the divergence in these two sectoral inflation rates has been more persistent since the Pandemic started.

The bottom panel shows that some countries are experiencing less inflation with the Covid basket. For these cases, there is no common explanation across countries. For example, in the Appendix I show that in Germany there was less Covid inflation because there was less weight on "Recreation and Culture," a category that had a surprising inflation rate of $4.23 \%$ 
during April, while in Ireland there was more weight on "Housing," which was having significant deflation that same month. Understanding the specific inflation dynamics within each of these country is outside the scope of this paper, but these results highlight the fact that the basket bias depends not only of the changes in the basket weights but also on the CPI sectoral inflation rates experienced by each country. So far, the Pandemic has led to a divergence in sectoral inflation rates that is causing higher Covid inflation in most countries, but the persistence of this result ultimately depends on how supply and demand shocks affect different sectors across countries.

Overall, my results outside the US should be used as approximations to the Covid inflation rates. Recognizing the potential bias stemming from the changes in consumption patterns, some NSOs have recently started to produce experimental indices with ad-hoc adjustments to the baskets, as in ONS (2020). Future research could help expand these efforts by computing Covid expenditure weights using high-frequency transactional data in each country.

\section{Conclusion}

There is growing awareness among academics, central bankers, and the financial media about the challenges of measuring and interpreting inflation measures during the Pandemic. ${ }^{10}$ A major concern is that consumption patterns are greatly affected by the lockdowns and social-distancing behaviors, introducing a potential bias into the measurement of CPI inflation.

Using estimates of the changes in consumption expenditures during the Pandemic, obtained from US credit and debit card transactions by Chetty et al. (2020), I update the basket of CPI weights and study the effect on on inflation in 18 countries. In most cases, I find that the Covid price index has more inflation than the official CPI. In particular, in the US the annual inflation rate by May 2020 was $0.95 \%$ with the Covid basket and only $0.13 \%$ with the official CPI weights. The difference is growing over time as consumers continue to spend more on food and similar categories experiencing inflation, and less on transportation and related categories with significant deflation. The difference is also present in the Core CPI, implying that the bias is not limited to consumer spending patterns on food and energy. Furthermore, I show that low-income households are experiencing more inflation during the crisis, with an annual inflation rate of $1.12 \%$ in May 2020, compared to just $0.57 \%$ for high-income households.

\footnotetext{
${ }^{10}$ See Diewert and Fox (2020), Tenreyro (2020), Lane (2020), and Wolf (2020).
} 
These results have important implications for policy-makers trying to respond to the crisis, as they suggest that the cost of living for consumers is higher than implied by the official CPI. The welfare implications are particularly relevant for lower-income households and extend to many countries experiencing a divergence in sectoral inflation rates. While the persistence of these effects is yet to be seen, the changes in consumer spending patterns during the first few months of the Pandemic have already produced a significant difference in inflation dynamics. 


\section{References}

Andersen, Asger Lau, Emil Toft Hansen, Niels Johannesen, and Adam Sheridan, "Consumer Responses to the COVID-19 Crisis: Evidence from Bank Account Transaction Data," Available at SSRN 3609814, 2020.

Argente, David and Munseob Lee, "Cost of Living Inequality during the Great Recession," SSRN Scholarly Paper ID 2567357, Social Science Research Network, Rochester, NY March 2017.

Baker, Scott R, R.A. Farrokhnia, Steffen Meyer, Michaela Pagel, and Constantine Yannelis, "How Does Household Spending Respond to an Epidemic? Consumption During the 2020 COVID-19 Pandemic," Working Paper 26949, National Bureau of Economic Research April 2020.

Bureau of Labor Statistics, "Consumer Price Index Archived News Releases : U.S. Bureau of Labor Statistics," https://www.bls.gov/bls/news-release/cpi.htm May 2020.

Carvalho, Vasco, Juan Ramón García, Stephen Hansen, Alvaro Ortiz, Tomasa Rodrigo, José V. Rodríguez Mora, and Pep Ruiz, "Tracking the COVID-19 Crisis through the Lens of 1.4 Billion Transactions," April 2020.

Cavallo, Alberto, Guillermo Cruces, and Ricardo Perez-Truglia, "Inflation Expectations, Learning, and Supermarket Prices: Evidence from Survey Experiments," American Economic Journal: Macroeconomics, 2017, 9 (3), 1-35.

Chetty, Raj, John N. Friedman, Nathaniel Hendren, and Michael Stepner, "RealTime Economics: A New Platform to Track the Impacts of COVID-19 on People, Businesses, and Communities Using Private Sector Data," 2020.

Coibion, Olivier and Yuriy Gorodnichenko, "Is the Phillips Curve Alive and Well after All? Inflation Expectations and the Missing Disinflation," American Economic Journal: Macroeconomics, 2015, 7 (1), 197-232.

_, _, and Michael Weber, "The Cost of the Covid-19 Crisis: Lockdowns, Macroeconomic Expectations, and Consumer Spending," Working Paper 27141, National Bureau of Economic Research May 2020. 
Curtin, Richard, "Surveys of Consumers: Preliminary Results from the June 2020 Survey," June 2020.

D’Acunto, Francesco, Ulrike Malmendier, Juan Ospina, and Michael Weber, "Exposure to Daily Price Changes and Inflation Expectations," Working Paper 26237, National Bureau of Economic Research September 2019.

Diewert, W. Erwin and Kevin J Fox, "Measuring Real Consumption and CPI Bias under Lockdown Conditions," NBER Working Paper 27144 May 2020.

Dunn, Abe, Kyle Hood, and Alexander Driessen, "Measuring the Effects of the COVID19 Pandemic on Consumer Spending Using Card Transaction Data," US Bureau of Economic Analysis Working Paper WP2020-5, 2020.

Hagemann, Robert P., "The Variability of Inflation Rates Across Household Types," Journal of Money, Credit and Banking, 1982, 14 (4), 494-510.

Hobijn, Bart and David Lagakos, "Inflation Inequality in the United States," review of income and Wealth, 2005, 51 (4), 581-606.

Jaravel, Xavier, "The Unequal Gains from Product Innovations: Evidence from the U.S. Retail Sector," The Quarterly Journal of Economics, May 2019, 134 (2), 715-783.

Kaplan, Greg and Sam Schulhofer-Wohl, "Inflation at the Household Level," Journal of Monetary Economics, November 2017, 91, 19-38.

Lane, Timothy, "Policies for the Great Global Shutdown and Beyond," https://www.bankofcanada.ca/2020/05/policies-great-global-shutdown-and-beyond/ May 2020 .

Michael, Robert T., "Variation Across Households in the Rate of Inflation," Journal of Money, Credit and Banking, 1979, 11 (1), 32-46.

ONS, "Prices Economic Analysis, Quarterly - Office for National Statistics," https://www.ons.gov.uk/economy/inflationandpriceindices/articles/priceseconomicanalysisquarterly/m May 2020.

Tenreyro, Silvana, "Monetary Policy during Pandemics: Inflatin before, during, and after Covid-19," in "Bank of England" April 2020. 
UN, "UN Classification of Individual Consumption According to Purpose (COICOP)," UN Statistics Division, 2018.

Wolf, Martin, "Inflation Figures Are about to Get Fuzzier," http://ftalphaville.ft.com/2020/04/27/1587998585000/Inflation-figures-are-about-to-getfuzzier/ May 2020. 